\title{
CLINICAL AND ANTIBACTERIAL ASSESSMENT OF RESIN INFILTRATE VERSUS COMPOMER AS PIT AND FISSURE SEALANTS
}

\author{
Mohamed H. Abo Nahas", Samy Y. El Biomy"*, Ibrahim F. Barakat "**
}

\begin{abstract}
Purpose: The aim of the present study was to assess the clinical and antibacterial effectiveness of resin infiltrate versus Compomer as a pit and fissure sealant. Materials and methods: This in-vivo study was carried out on two hundred, young permanent molars of children ranging from six to twelve years of age. The teeth were equally divided into two groups (100 teeth each), based on the sealant material used in sealing the deep pits and fissures. Result: There was significance difference between the antibacterial effect of the Resin infiltration (ICON) and Compomer while there was significant difference between the clinical retention of Resin infiltration (ICON) and Compomer. Conclusion: Compomer has superior antibacterial action against streptococcus mutans than Resin infiltration (ICON). While Resin Infiltration has superior clinical retention than Compomer.
\end{abstract}

\section{INTRODUCTION}

Despite major advances in preventive dentistry in the past decades, dental caries remains one of the most significant oral conditions in young children and is a major cause of dental abscesses and tooth ache.

The main etiological factors associated with dental caries-namely mutants streptococci which includes Streptococcus mutans and streptococcus sorbinus, sugar, and susceptible tooth. Surfaces ${ }^{(1,2)}$. There is a clear relationship between dental caries and mutans streptococci. After dental eruption, these microorganisms colonize different tooth surfaces. Fissures form a good reservoir, and even when they are not carious, they harbor mutans streptococci ${ }^{(3)}$.

The pits and fissures, which forms mechanical retention niches for bacteria, food, and other debris, allow the initiations of enamel demineralization ${ }^{(4)}$. Preventive measure such as control of bacterial plaque and topical application of fluoride solutions have little effect on these surfaces, more effective measure are therefore necessary, such as the application of occlusal sealants ${ }^{(5)}$. As a result, the carcinogenic microorganisms present in these fissures lose their viability. It has been suggested that this positive effect could possibly be enhanced by adding fluoride to the sealant material ${ }^{(6)}$.

Caries infiltration is the new era in the conservative dentistry, The aim of the resin infiltration technique is to allow its penetration by capillarity into the porous enamel, stopping the demineralization process, stabilizing the caries lesion and forming a mechanical barrier, depriving the bacteria that colonize the lesion of the oral biofilm nutrients ${ }^{(1,}$ 5). Hence, it was been suggested for use as pit and fissure sealant. The capacity of a sealant to prevent dental decay relies directly upon the ability of the sealant material to thoroughly fill pits, fissures, and/ or morphological defects and remain completely intact and bonded to enamel surfaces for a life time $^{(7)}$. The success of fissures sealants depends on the sealant retention, maintenance of integrity and the properties of the sealant materials ${ }^{(8)}$.

\footnotetext{
* Dentist at Egyptian Ministry of Health.

** Professor, Pedodontics and Oral Health Department, Faculty of Dental Medicine, Boys-Cairo, Al-Azhar University. *** Assistant Professor, Pedodontics and Oral Health Department, Faculty of Dental medicine, Boys, Cairo, ALAzhar University.
} 


\section{MATERIALS AND METHODS}

This in-vivo study was carried out in Pedodontics and Oral Health Department, Faculty of Dentistry, Al-Azhar University, boys, Cairo.Two hundred, young permanent molars of children ranging from six to twelve years of age. The teeth were equally divided into two groups (100 teeth each), based on the sealant material. After polishing the selected tooth with prophy jet and isolation with a rubber dam, the permanent molar of one side delivered ICON ${ }^{\circledR}$ as Resin infiltration and the permanent molar of the other side delivered Compoglass Flow ${ }^{\circledR}$ as Compomer other side. The two materials applied according to the manufacture instructions without modification. After rubber dam removal the child asked to rinse his mouth then the first microbiological sample (baseline) was collected using a sterile intraoral swab from the buccal and occlusal surface. The sample preserved in a sterile screw capped tube containing $9 \mathrm{ml}$ Thioglycolate broth media and transferred to the microbiological laboratory to be cultured on Mitissalivaris agar and bacterial counting. After one month the child asked not to brush his teeth in the day of sampling then the second sample was collected from the sealant surface using the sterile cotton, then after three months the same steps were done collecting the third sample.

Clinical evaluations were done 3 and 6 months after sealant application. The following criteria will be adopted to evaluate the retention of the sealant ${ }^{(9)}$. Total Retention (TR) : total retention of sealant on the occlusal surface; Partial Retention Type 1 (PR1): presence of sealant in $2 / 3$ of the pit extension, with small fractures and losses of material, Partial Retention Type 2 (PR2): presence of sealant in $1 / 3$ of the pit extension with fractures and losses of material, Total Loss (TL) : absence of sealant on the occlusal surface.

Data were tabulated in Excel worksheets, and statistical analysis was performed with SPSS (Chi., IL, USA) software. Descriptive statistics were presented as mean \pm standard deviation for each group of primary anterior teeth. The results were analyzed using Student's t-test, and significant differences were defined as $\mathrm{P}<0.05$.

\section{RESULTS}

For ICON group there was a statistically significant decrease in $\mathrm{S}$. mutans count after one month and no statistically significant after three months. For Compomer group there was no statistically difference of S. mutans count after one month and after three months. After one month there was a statistically significant difference between ICON and Compomer where $\mathrm{p}=0.01$. The highest mean value was found in ICON group while the least mean value was found in Compomer group. After three months there was a statistically significant difference between ICON group and Compomer group where $\mathrm{p}=0.01$. The highest mean value was found in ICON while the least mean value was found in Compomer (Table $1 \&$ Fig. 1).

TABLE 1: Comparison between the S.M counts of both groups during all the follow up periods.

\begin{tabular}{|c|c|c|c|c|c|c|c|}
\hline \multirow{2}{*}{ Variables } & \multicolumn{2}{|c|}{ Immediately postoperative } & \multicolumn{2}{|c|}{ After 1 month } & \multicolumn{2}{|c|}{ After 3 months } & \multirow[t]{2}{*}{ p-value } \\
\hline & Mean & SD & Mean & SD & Mean & SD & \\
\hline Icon & $4.07^{\mathrm{aB}}$ & 0.09 & $4.11^{\mathrm{aA}}$ & 0.09 & $4.24^{\mathrm{aAB}}$ & 0.35 & $0.030 *$ \\
\hline Compomer & $3.60^{\mathrm{Aa}}$ & 1.32 & $3.80^{\mathrm{bA}}$ & 0.35 & $3.91^{\mathrm{bA}}$ & 0.11 & $0.456 \mathrm{~ns}$ \\
\hline p-value & \multicolumn{2}{|c|}{$0.277 \mathrm{~ns}$} & \multicolumn{2}{|c|}{$0.014 *$} & \multicolumn{2}{|c|}{$0.010 *$} & \\
\hline
\end{tabular}

Means with different small letters in the same column indicate statistically significance difference; means with different capital letters in the same row indicate statistically significance difference. *; significant $(p<0.05) n s$; non-significant $p>0.05$ 


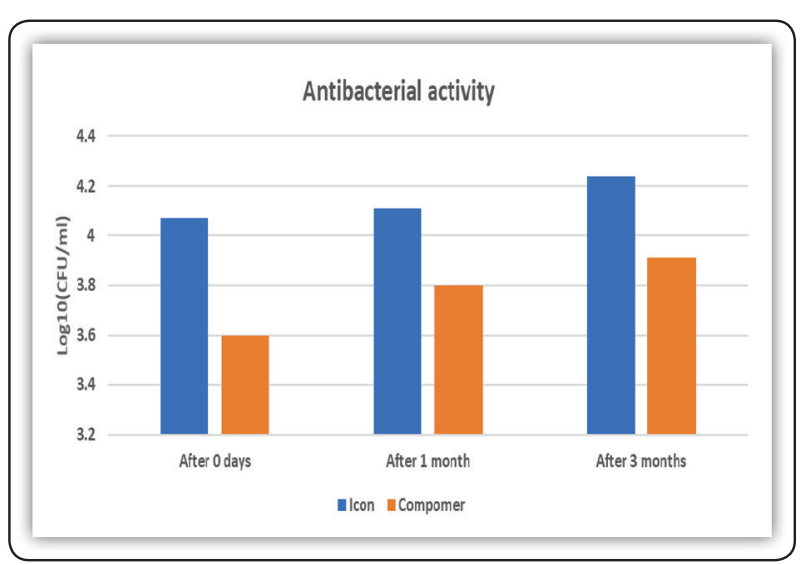

FIG (1) Bar chart representing antibacterial activity of different group

Regarding the clinical assessment results, after 3 months a significant different between the total retention of ICON and Compomer groups $(\mathrm{p}=.001)$. Meanwhile, after 6 months, there was a significant different between the total retention of ICON and Compomer groups $(\mathrm{p}=.014)$ (Table $2 \&$ Fig. 2).

TABLE (2) Comparison between the retention basement of both Compomer and ICON.

\begin{tabular}{|c|c|c|c|c|c|c|}
\hline \multirow{3}{*}{\multicolumn{2}{|c|}{ Variables }} & \multicolumn{5}{|c|}{ Clinical assessment } \\
\hline & & \multicolumn{2}{|c|}{ Icon } & \multicolumn{2}{|c|}{ Compomer } & \multirow{2}{*}{$\mathrm{p}$-value } \\
\hline & & $\mathrm{N}$ & $\%$ & $\mathrm{~N}$ & $\%$ & \\
\hline \multirow{4}{*}{3 months } & TR & 100 & $100 \%$ & 90 & $90 \%$ & \multirow{4}{*}{$0.001 *$} \\
\hline & PR1 & 0 & $0 \%$ & 9 & $9 \%$ & \\
\hline & PR2 & 0 & $0 \%$ & 1 & $1 \%$ & \\
\hline & TL & 0 & $0 \%$ & 0 & $0 \%$ & \\
\hline \multirow{4}{*}{6 months } & TR & 90 & $90 \%$ & 75 & $75 \%$ & \multirow{4}{*}{$0.014 *$} \\
\hline & PR1 & 2 & $2 \%$ & 20 & $20 \%$ & \\
\hline & PR2 & 0 & $0 \%$ & 3 & $3 \%$ & \\
\hline & TL & 8 & $8 \%$ & 2 & $2 \%$ & \\
\hline
\end{tabular}

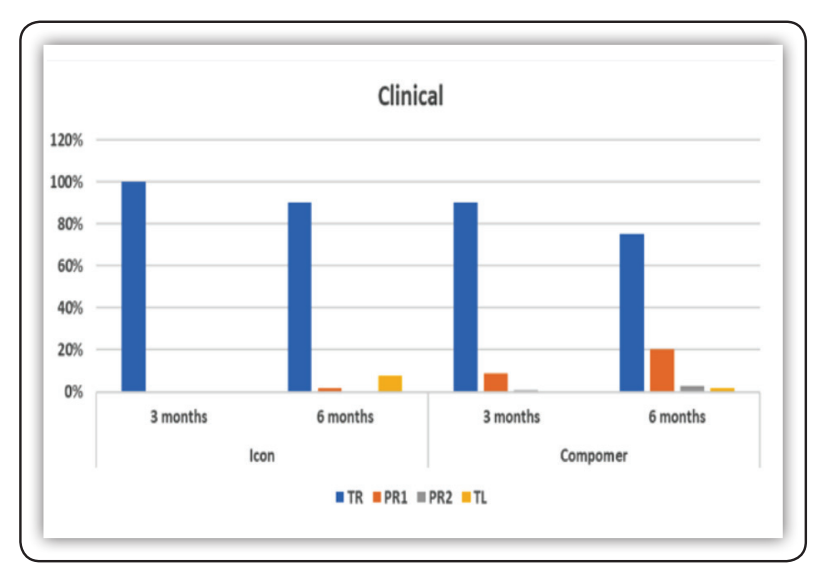

FIG (2) Bar chart representing the retention basement of both Compomer and ICON

\section{DISCUSSION}

In the current study, the rate of increase in SM counts was compared in both groups over time. Non-significant difference was found in the rate of increase of SM among the compomer group. This might be attributed to the antibacterial activity of fluoride released from compomer in dental plaque and in agreement with Pinar who found that Fluoride concentrations in plaque can exert inhibitory effects on oral microflora growth ${ }^{(10)}$. Where van Loveren, in his in vitro experiments have demonstrated that the acid production of S.M. and lactobacilli was reduced in layers overlying fluoridated enamel ${ }^{(11)}$.

On the other hand, significant difference was found between the compomer group and ICON group, After one month. This difference is in agreement with Arslan in vitro study comparing the bacterial adhesion and count adjacent to ICON and Enamel Pro Varnish ${ }^{(12)}$. The same conclusion existed in Hallgren et al. who found significantly higher fluoride concentration and lower level of S.M adjacent to glass ionomer compare to that adjacent to resin composite and concluded that the use of glass ionomer creates a local ecological condition that affects the establishment of S.M, thus a less caries inducing micro flora may develop. 
Although, a significant difference of the S.M count in both groups after one month was existed but it was much less in value in comparable to that found in Hallgren et al. study. This may be contributed to that this study is designed with the concept of split mouth technique, which permits the crossover of fluoride from compomer segment to ICON segment ${ }^{(13)}$.

These results were in disagreement with Wright et al., Hong et al and Mota et al. who found no significant difference in plaque adjacent to glass ionomer compared to composite resin ${ }^{(14-16)}$. This may be contributed to that; their experiments were about the use of hybrid glass ionomer and composite resin as bonding material for the brackets of fixed orthodontic appliance using the split mouth technique which cause more crossover of fluoride from hybrid glass ionomer segment to the composite segment. This might be the cause of non-significant difference between the two materials and reduce the power of the experiment to find a difference as stated by Benson et $\mathrm{al}^{(13)}$.

Moreover, after three months, S.M counts increase in plaque adjacent to ICON more than the S.M counts increase in the plaque adjacent to compomer. This result was found to be statistically significant and was also in agreement with the study conducted by Soly et al., fluoride varnish was more effective in reducing bacterial adhesion compared with resin infiltrate $(\mathrm{ICON})^{(12)}$.

In the current study, the Clinical results showed a significant difference between Compoglass flow and ICON regarding the total retention, partial retention and total loss along the 3 and 6 months follow up periods, this explain the superior retention capability of infiltration as a fissure sealant over Polyacid-modified resin-based fissure sealants (Compomer), and this comes in agreement with Yakut et. al. who compared resin sealant vs. polyacid-modified resin composite in two year clinical study ${ }^{(17)}$. and in disaggrement with Puppin-
Rontanet.al study who found no sinificant difference regarding total retention of both Compoglass flow versus Flouroshieled which is resin based sealant, after two years study ${ }^{(4)}$.

\section{CONCLUSION}

Compomer (Compoglass flow) has superior antibacterial effect against streptococcus mutans superior to resin infiltration (ICON). While Resin infiltration (ICON)has a better clinical retention as a fissure sealant than Compomer (Compoglass flow).

\section{RECOMMENDATIONS}

It is recommended to investigate the bacterial adhesion on ICON compared to one of other nonfluoride releasing resin-based fissure sealant without using split mouth technique. Also,

Longer period of follow up is needed to test the clinical retention of resin infiltration system $\left(\mathrm{ICON}^{\circledR}\right)$ as a fissure sealant.

\section{REFERENCES}

1. Law V, Seow WK. A longitudinal controlled study of factors associated with mutans streptococci infection and caries lesion initiation in children 21 to 72 months old. Pedo. dent. 2006;28(1):58-65.

2. Leme AP, Koo H, Bellato C, Bedi G, Cury J. The role of sucrose in cariogenic dental biofilm formation-new insight. J. dent. res. 2006;85(10):878-87.

3. Baca P, Castillo A, Bravo M, Junco P, Baca A, Llodra J. Mutans streptococci and lactobacilli in saliva after the application of fissure sealants. Oper. dent. 2002;27(2): 107-11.

4. Puppin-Rontani R, E Baglioni-Gouvea M, F deGoes M, Garcia-Godoy F. Compomer as a pit and fissure sealant: Effectiveness and retention after 24 months2006. 31-6 p.

5. Subramaniam P, Konde S, Mandanna D. Retention of a resin-based sealant and a glass ionomer used as a fissure sealant: a comparative clinical study. J. India. Society of Pedo. and Prev. Dent. 2008;26(3):114.

6. Naorungroj S, Wei H-H, Arnold RR, Swift Jr EJ, Walter R. Antibacterial surface properties of fluoride-containing resin-based sealants. J. den. 2010;38(5):387-91. 
7. Amin HE. Clinical and antibacterial effectiveness of three different sealant materials. American Dental Hygienists Asso. 2008;82(5):45-

8. Yildiz E, Dörter C, Efes B, Koray F. A comparative study of two fissure sealants: a 2-year clinical follow-up. J. of oral rehab. 2004;31(10):979-84.

9. Pereira A, Basting R, Pinelli C, Werner C. Retention and caries prevention of Vitremer and Ketac-bond used as occlusal sealants. American j. deny. 1999;12(2):62-4.

10. Erdem AP, Sepet E, Kulekci G, Trosola SC, Guven Y. Effects of two fluoride varnishes and one fluoride/chlorhexidine varnish on Streptococcus mutans and Streptococcus sobrinus biofilm formation in vitro. Inter. j. med. sciences. 2012;9(2):129.

11. Van Loveren C.Antimicrobial activity of fluoride and its in vivo importance: identification of research questions. Caries res. 2001;35(Suppl. 1):65-70.

12. Aziznezhad M, Alaghemand H, Shahande Z, Pasdar N, Bijani A, Eslami A, et al. Comparison of the effect of resin infiltrant, fluoride varnish, and nano-hydroxy apatite paste on surface hardness and streptococcus mutans ad- hesion to artificial enamel lesions. Electronic Physician. 2017;9(3):3934-42.

13. Benson P, Shah A, Millett D, Dyer F, Parkin N, Vine R. Fluorides, orthodontics and demineralization: a sys. rev. J. ortho. 2005;32(2):102-14.

14. Ai H, Lu H-F, Liang H-Y, Wu J, Li R-L, Liu G-P, et al. Influences of bracket bonding on mutans streptococcus in plaque detected by real time fluorescence-quantitative polymerase chain reaction. Chinese med. j. 2005;118(23).

15. Mota SM, Enoki C, Ito IY, Elias AM, Matsumoto MAN. Streptococcus mutans counts in plaque adjacent to orthodontic brackets bonded with resin-modified glass ionomer cement or resin-based composite. Braz. oral res. 2008; 22(1):55-60

16. Wright AB, Lee RT, Lynch E, Young KA. Clinical and microbiologic evaluation of a resin modified glass ionomer cement for orthodontic bonding. America. j. ortho. and dentofacial orthoped. 1996;110(5):469-75.

17. Yakut N, Sonmez H. Resin composite sealant vs. polyacidmodified resin composite applied to post eruptive mature and immature molars: two year clinical study. J. clinical pedo. dent. 2006;30(3):215-8. 